\title{
Primary Malignant Lymphoma of the Trachea and Subglottic Region
}

\author{
Hideo Kobayashi, Yoshikazu Nemoto, Kenji Namiki, Kenji Nakazawa and Makio Mukai*
}

\begin{abstract}
A 44-year-old female was admitted with the complaint of choking. On fiberbronchoscopic examination, multiple, polypoid lesions with a smooth surface were exhibited at the cervical trachea. Histological diagnosis was B-cell malignant lymphoma, diffuse, medium sized cell type (LSG classification). No other lesions were detected in the systemic evaluation. After combined chemotherapy and regional irradiation, the tumor disappeared. The clinical and pathological characteristics of this case are similar to those of malignant lymphoma of mucosa-associated lymphoid tissue (MALT).
\end{abstract}

(Internal Medicine 31: 655-658, 1992)

Key words: retrograde tracheo-laryngo fiberscopy, B-cell lymphoma, mucosa-associated lymphoid tissue (MALT), bronchus-associated lymphoid tissue (BALT)

\section{Introduction}

There are a few reports of primary malignant lymphoma of the trachea (1-3) and the larynx (4-7). Recently, Isaacson et al proposed the entity of malignant lymphoma of mucosa-associated lymphoid tissue (MALT) which shows a favorable clinical course and similar pathological findings $(8-10)$. Primary pulmonary lymphoma originating from bronchus-associated lymphoid tissue (BALT) was thought to be included in this entity (11-13). This is the first case report of primary tracheal and subglottic lymphoma in Japan and we suggest that primary B-cell lymphoma of the trachea and larynx show the same characteristics of the malignant lymphoma of MALT.

\section{Case Report}

A 44-year-old woman was emergently admitted on August 1990 with the complaint of hoarseness and difficulty of breathing. Inspiratory and expiratory coarse rhonchi (stridor) were auscultated throughout over the lung, and large airway obstruction was suspected. Laboratory examinations showed no significant abnormalities except mild hypoxemia. Chest roentgenogram was almost normal, however, the cervical roentgenogram revealed irregular polypoid lesions protruding into the tracheal lumen (Fig. 1).
For the relief of choking, tracheostomy was performed. Through the stoma of the tracheostomy, "retrograde tracheo-laryngo fiberscopy" was introduced. Multiple, small and irregular, polypoid lesions, extending to the right vocal cord, narrowed the tracheal lumen and subglottic region (Fig. 2). These lesions had a smooth surface and were thought to be present in the submucosa. The endoscopic findings of the lesion seemed to mimic the so-called bronchial adenoma (tumors of bronchial gland origin) (14), however, their distribution encircled the trachea, suggesting a malignant character.

Using laryngo-micro surgery, the polypoid lesions were biopsied. Histological examination showed a dense proliferation of lymphoid cells beneath the intact tracheal mucosa (Fig. 3). These lymphoid cells were of intermediate size, slightly larger than small lymphocytes, with hyperchromatic, round or irregularly-shaped nuclei. The cytoplasm was almost clear and the cell margins were well defined (Fig. 4). These findings were compatible with centrocyte-like cells, clear cell variant (10). Immunohistochemical staining of lymphoid cells was positive for B-cell marker (L-26) (Fig. 5) and negative for T-cell marker (UCHL-1). The diagnosis was B-cell malignant lymphoma, diffuse, medium-sized cell type (LSG classification).

Staging of the lymphoma, using peripheral blood, bone marrow, computed tomography of the chest and abdomen, bone scintigram, and gallium scintigram, was

From the Department of Internal Medicine, Division of Respiratory Disease, Saiseikai Utsunomiya Hospital, Utsunomiya and * the Division of Surgical Pathology, Central Clinical Laboratories, Keio University Hospital, Tokyo

Received for publication July 16, 1991; Accepted for publication December 28, 1991

Reprint requests should be addressed to Dr. Hideo Kobayashi, the Department of Internal Medicine, Division of Respiratory Disease, Saiseikai Utsunomiya Hospital, 4-17 Chuohonmachi, Utsunomiya 


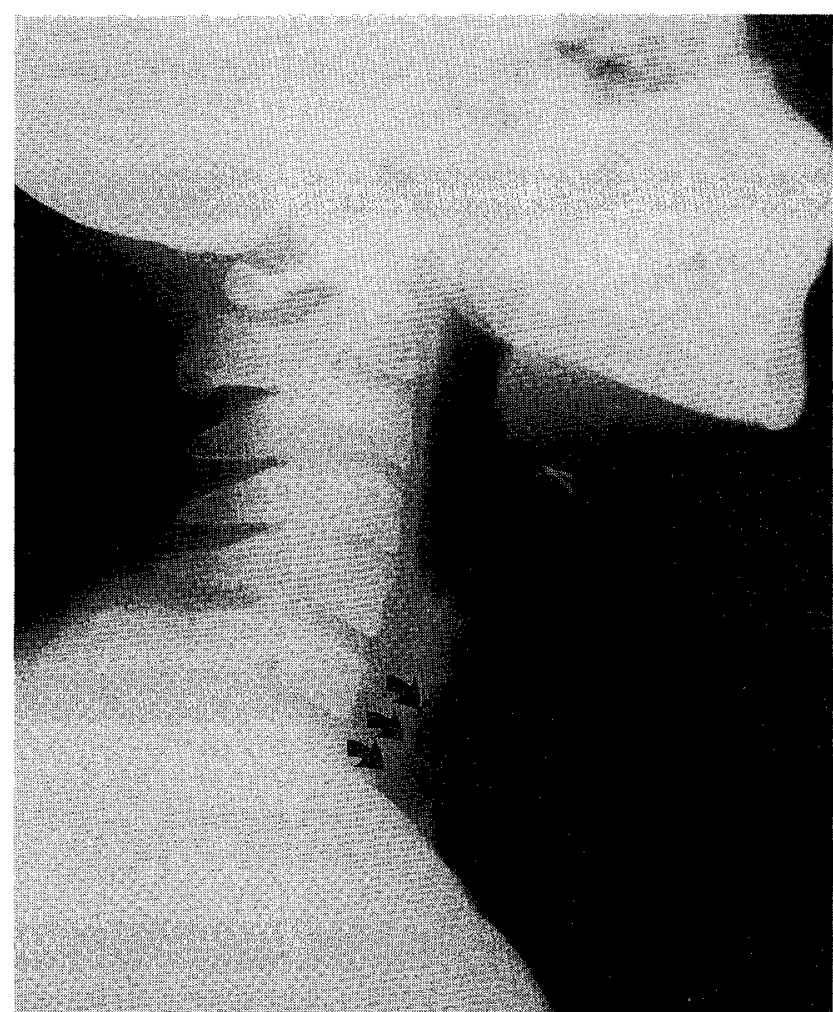

Fig. 1. Lateral view of the cervical trachea. Irregular polypoid lesions were present in the tracheal lumen (curved arrows).

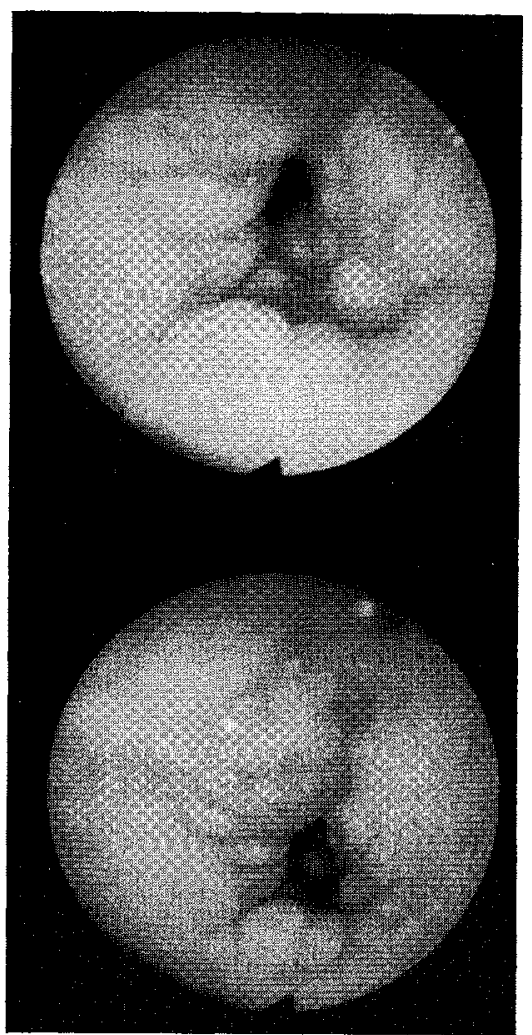

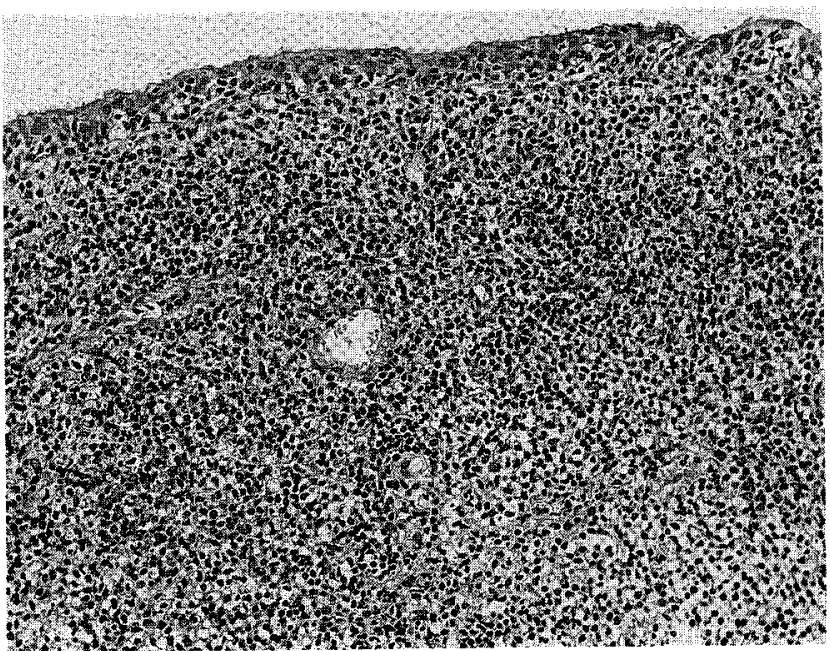

Fig. 3. Histological findings of the biopsied specimen A. dense proliferation of lymphoid cells was revealed beneath the aimost normal mucosal epithelia. (HE stain, $\times 200$ ).

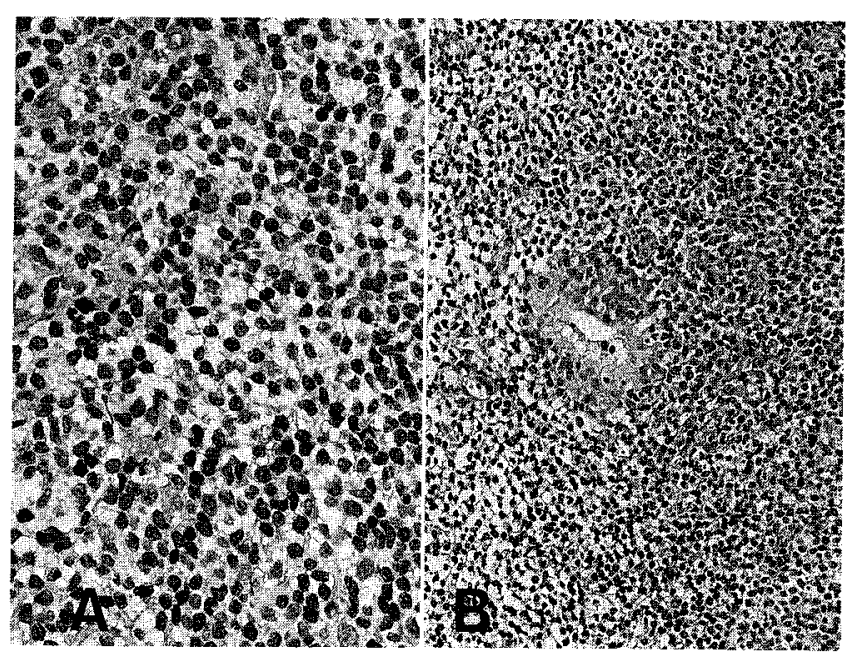

Fig. 4. A) Histological examination of the biopsied specimen. The infiltrated lymphoid cells were of intermediate size with hyperchromatic round or irregularly-shaped nuclei (centrocyte-like cells). Histological diagnosis was malignant lymphoma, diffuse, medium-sized cell type by LSG classification. H. E. stain, original magnification : $\times 400$. B) The centrocyte-like cells invade the base of a tracheal gland and form the lymphoepithelial lesion. (HE stain, $\times 200$ ).

Fig. 2. The findings through retrograde (trans-stomal) tracheo-laryngofiberscopy. The tracheal lumen was narrowed by irregular polypoid lesions which extended under the vocal cord. 


\section{Malignant Lymphoma of the Trachea}

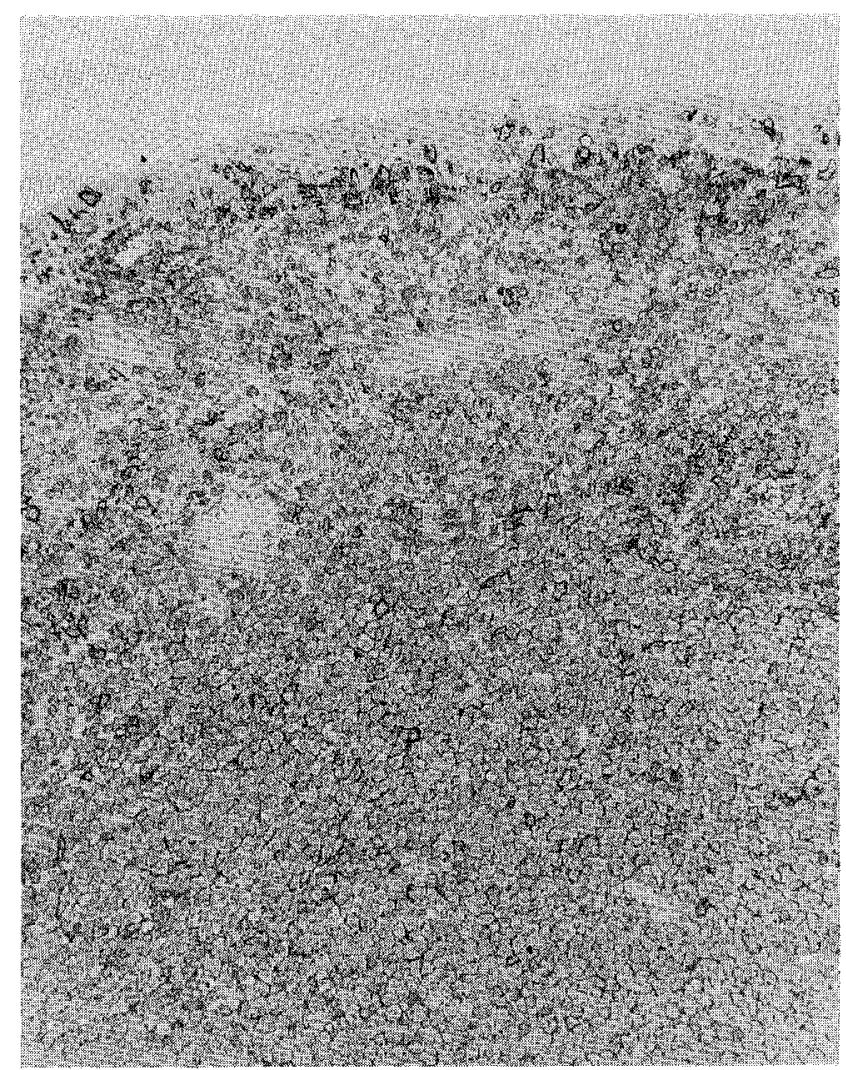

Fig. 5. Immunohistochemical staining for L-26. Almost all of the lymphoid cells are strongly positive $(\times 200)$.

performed, however, no lesions could be detected. Also, she denied the sicca symptoms of Sjögren syndrome $(3,15)$. Thus, we concluded that the trachea and subglottic region was the primary site, stage $1 \mathrm{E}$ (Ann Arbor).

Twelve courses of combined chemotherapy with MTX, ADM, CTX, VCR, PDN, and BLM followed by $30 \mathrm{~Gy}$ irradiation resulted in complete remission of the polypoid lesions, confirmed by fiberbronchoscopy, computed tomography and cervical roentgenogram. There was no sign of recurrence at the one-year followup examination.

\section{Discussion}

Primary malignant lymphoma of the trachea and subglottic region is extremely rare; only one similar case report (6) could be found. Furthermore, there were four reported cases of primary subglottic lymphoma in the Japanese literature (4) and three cases of primary tracheal lymphoma in the English language literature $(1-3)$. Thus, there is little conclusive information on the pathogenesis and treatment for this disease. However, it is important for pulmonologists to examine the upper airway if signs or symptoms of central airway obstruction are present.

Recently, primary pulmonary lymphoma has been considered to originate from bronchial-associated lymphoid tissue (BALT) $(11-13)$, and it is thought to be included in the concept of malignant lymphoma of mucosa-associated lymphoid tissue (MALT) (8-10). The entity of MALT-derived lymphoma also includes gastric, salivary gland, and thyroid gland lymphomas and shows a good response to treatment and a favorable prognosis (10). The histological characteristics and response to treatment of this case were similar to MALTderived lymphoma. Also, there were no significant differences between the structure of bronchi and trachea. Therefore, we suggest that primary malignant lymphoma of the trachea (and the subglottic region) might be included in the entity of malignant lymphoma of MALT.

The subglottic region and cervical trachea is considered as the area dividing the respiratory department and otolaryngology department. For direct observation of this region, "retrograde tracheo-laryngo fiberscopy" (trans-stomal fiberscopy) was adequate $(3,16)$. In this case, these lesions were also detectable by the typical trans-oral fiberbronchoscopy, however, the vocal fold would have made visualization of the polypoid lesion more difficult. The tracheostomy could simplify the fiberscope insertion and adverted the risk of choking. The fiberoptic appearance of primary tracheal lymphoma has not been precisely discussed in previous reports. The smooth surfaced, irregular polypoid lesions reflected the histological findings, that is, a proliferation of lymphoma cells under intact mucosa. The appearance was nearly the same as the primary pulmonary lymphoma which we reported previously (17).

In conclusion, we reprorted based on the findings and treatment response in this case of primary malignant lymphoma of the trachea and subglottic region, we propose that this case might be included in the concept of MALT-derived malignant lymphoma.

Acknowledgments: The writers thank Dr. T. Inoue and Dr. T. Harada, Department of Otolaryngology, Saiseikai Utsunomiya Hospital, for their cooperation.

\section{References}

1) Pradhan DJ, Rabuzzi D, Meyer JA. Primary solitary lymphoma of the trachea. J Thorac Cardiovasc Surg 70: 938, 1975.

2) Maeda M, Kotake $Y$, Monden $Y$, Nakahara K. Kawashima $\mathrm{Y}$, Kitamura H. Primary malignant lymphoma of the trachea. Report of a case successfully treated by primary end-to-end anastomosis after circumferential resection of the trachea. $\mathfrak{J}$ Thorac Cardiovase Surg 81: 835, 1981.

3) Kamhoz S, Sher A, Barland P, Rosen N, Rakoff S, Becker N. Sjögren syndrome: Severe upper airways obstruction due to primary malignant tracheal lymphoma developing during successful treatment of lymphocytic interstitial pneumonitis. $J$ Rheumatology 14: 588, 1987.

4) Masuda S, Uchida M, Kawabata K. Malignant lymphoma of the larynx. Otolaryngology-Head Neck Surg (Tokyo) 62: 45, 1990 (in Japanese).

5) Gregor RT. Laryngeal malignant lymphoma-An entity? J 


\section{Kobayashi et al}

Laryngol Otol 95: 81, 1981.

6) Levine HL, Tubbs R. Nonsquamous neoplasms of the larynx. Otolaryngol Clin North Am 19: 475, 1986.

7) Morgan K, Maclennan KA, Narula A, Bradley PJ, Morgan DAL. Non-Hodgkin's lymphoma of the larynx (Stage 1E). Cancer 64: 1123, 1989.

8) Isaacson P, Wright DH. Malignant lymphoma of mucosa-associated lymphoid tissue. A distinctive type of B-cell lymphoma. Cancer 52: 1410, 1983.

9) Isaacson P, Wright DH. Extranodal malignant lymphoma arising from mucosa-associated lymphoid tissue. Cancer 53: 2515, 1984.

10) Isaacson $P G$, Spencer J. Malignant lymphoma of mucosa-associated lymphoid tissue. Histopathology 11: 445, 1987.

11) Rose RM, Grigas D, Strattemeir E, Harris NL, Liggood RM. Endobronchial involvement with non-Hodgkin's lymphoma. A Clinical-radiologic analysis. Cancer 57: 1750, 1986.

12) Spapen H, Ecckhout E, Volckaert A, Dehou MF, Schandevyl W, van Camp B. Primary endobronchial non-Hodgkin's lymphoma: report of two cases and review of the literature. Netherlands $J$ Med 33: 86, 1988.

13) Li G, Hansmann M-L, Zwingers $T$, Lennert K. Primary lymphomas of the lung: morphological, immunohistochemical and clinical features. Histopathology 16: 519, 1990.

14) Carter D, Eggleston JC. Tumors of the Lower Respiratory Tract. Armed Forces Institute of Pathology, Washington, D.C., 1983, p. 189

15) Kobayashi H, Matsuoka R, Tsunoda N, Saito K. Sjögren syndrome with multiple bullae and pulmonary nodular amyloidosis. Chest 94: 438, 1988.

16) Barzo P, Szakacs G. Retrograde tracheo-laryngofiberscopy. J Jpn Soc Bronchology 6: 185, 1984 (in Japanese).

17) Maehara $T$, Kobayashi $H$, Kaneko $K$, Naruse $T$. A case of T-cell malignant lymphoma of the lung. Jpn J Thorac Dis 29: 469, 1991 (in Japanese). 